\title{
Transcription of Two Blue Copper-Binding Protein Isogenes Is Highly Correlated with Arbuscular Mycorrhizal Development in Medicago truncatula
}

\author{
István Parádi,, ${ }^{1,2}$ Diederik van Tuinen, ${ }^{1}$ Dominique Morandi, ${ }^{1}$ Sergio Ochatt, ${ }^{3}$ Franck Robert, ${ }^{1}$ \\ Louis Jacas, ${ }^{3}$ and Eliane Dumas-Gaudot ${ }^{1}$ \\ 1UMR 1088 INRA/5184 CNRS/Université de Bourgogne, Plante-Microbe-Environnement, INRA-CMSE, Dijon BP 86510, \\ 21065 Dijon Cedex, France; ${ }^{2}$ Department of Plant Physiology and Molecular Plant Biology, Eötvös Loránd University, 1/c \\ Pázmány Péter stny., 1117 Budapest, Hungary; ${ }^{3}$ UMR LEG, Laboratoire de Physiologie Cellulaire, Morphogenèse et \\ Validation, INRA
}

Submitted 26 August 2009. Accepted 26 April 2010.

Expression profiling of two paralogous arbuscular mycorrhizal (AM)-specific blue copper-binding gene (MtBcpla and $M t B c p 1 b)$ isoforms was performed by real-time quantitative polymerase chain reaction in wild-type Medicago truncatula Jemalong 5 (J5) during the mycorrhizal development with Glomus intraradices for up to 7 weeks. Timecourse analysis in $\mathrm{J5}$ showed that expression of both $\mathrm{MtBcp} 1$ genes increased continuously and correlated strongly with the colonization intensity and arbuscule content. MtPT4, selected as a reference gene of the functional plant-fungus association, showed a weaker correlation to mycorrhizal development. In a second experiment, a range of mycorrhizal mutants of the wild-type J5 was assessed. Strictly AMpenetration-defective TRV25-C and TRV25-D (dmi3, Mtsym13), hypomycorrhizal TR25 and TR89 (dmi2, Mtsym2) mutants, and a hypermycorrhizal mutant TRV17 (sunn, Mtsym12) were compared with J5 3 and 7 weeks after inoculation. No MtBcpl transcripts were detected in the mutants blocked at the appressoria stage. Conversely, TR25, TR89, and J5 showed a gradual increase of the expression of both MtBcpl genes in 3- and 7-week-old plants, similar to the increase in colonization intensity and arbuscule abundance. The strong correlation between the expression level of AM-specific blue copper-binding protein-encoding genes and AM colonization may imply a basic role in symbiotic functioning for these genes, which may serve as new molecular markers of arbuscule development in M. truncatula.

Arbuscular mycorrhizal (AM) symbiosis is an ancient and widely spread type of fungal-plant interaction, with the earliest fossil evidence originating from the Ordovician period (Redecker et al. 2000), and is formed by the vast majority of terrestrial plant species all over the world. Fungal partners belonging to the Glomeromycota phylum are obligate biotrophs (Schuessler et al. 2001). For host plants, nutrient uptake (espe-

Current address for István Parádi: Department of Plant Physiology and Molecular Plant Biology, Eötvös Loránd University, 1/c Pazmany Peter stny, 1117 Budapest, Hungary.

Corresponding author: István Parádi; E-mail: iparadi@ caesar.elte.hu

* The $\boldsymbol{e}$-Xtra logo stands for "electronic extra" and indicates that three supplementary figures and one supplementary table are published online. cially P) seems to be the most important, while they provide carbohydrates to their fungal partners. AM plants have unique physiological characteristics, such as enhanced photosynthesis and shoot/root ratio and changes in hormonal balances and metabolite levels. Although the positive growth response of host plants to mycorrhiza formation usually declines under certain environmental conditions (e.g., high $\mathrm{P}$ availability), AM plants generally build up a higher resistance to abiotic and biotic stresses (Smith and Read 2008).

Development of AM symbiosis requires a bilateral coordination of complex cellular processes, such as formation of fungal appressoria at the root surface, development of prepenetration apparatus within epidermal and then cortical layers, penetration into host root cells, and differentiation of the highly branched specific intracellular structures, the arbuscules within the cortex, thought to be the main sites of nutrient exchange (Gianinazzi-Pearson 1996; Bonfante and Genre 2008). Arbuscules are among the most unique and specialized symbiotic interfaces between two eukaryotes, which are formed actively by both symbiotic partners. They are relatively short lived, functioning for approximately 10 days for the most rapidly growing crop plants (Alexander et al. 1988). Arbuscule formation is accompanied by the reorganization of cytoskeleton and endoplasmic reticulum (Genre and Bonfante 1998), penetration of the fungal hypha through the cortical cell wall and its dichotomous branching intracellularly, formation of an extended plastid network surrounding arbuscules (Fester et al. 2001), as well as the formation of the periarbuscular membrane (PAM), a functionally specialized plant membrane that separates the arbuscules from the plant cytoplasm (Dexheimer et al. 1985).

By comparison with the much better-studied Rhizobium spp.-legume symbiosis, molecular investigations of AM fungi are hindered by the inability to grow them independently of their plant hosts. Interactions between both symbiotic partners are complex and apparently do not rely on one or a few easily identifiable genes or molecules. Targeted approaches identified a few arbuscule-specific genes, including the phosphate transporter MtPT4, which imports fungus-derived $\mathrm{P}_{\mathrm{i}}$ into the cortical cells (Harrison et al. 2002). Downregulation of MtPT4 is detrimental for the development of AM symbiosis in loss-offunction mutants (Javot et al. 2007) and, due to its high specificity, MtPT4 is often used as a marker of gene expression in the PAM of Medicago truncatula. Recent nontargeted gene isolation approaches and microarray experiments have identified several new plant genes (especially in M. truncatula) 
expressed specifically in AM roots, exposing the peculiar and highly specific nature of the molecular background of AM symbiosis (Liu et al. 2003; Wulf et al. 2003; Grunwald et al. 2004; Hohnjec et al. 2005). Many of these newly characterized genes could not be unambiguously positioned in any functional group, despite their characteristic structure and consistently higher expression rates, like blue copper-binding proteins.

Single- or multi-copper blue copper proteins (Bcps) are characterized by the blue copper-binding domain responsible for their characteristic blue color. They include a large number of diverse homologues, in terms of sequence similarity (as low as $10 \%$ identity), while the overall structural fold of the domain, consisting of eight $\beta$ strands, is generally conserved (Nakamura and Go 2005).

AM-specific Bcp-like genes were first identified in M. truncatula by Journet and associates (2002), who characterized two highly similar basic $M t B c p$ genes specifically upregulated in AM symbiotic conditions by a large-scale expressed sequence tag (EST) analysis (Medicago EST Navigation System [MENS] cluster IDs MtC30378 and MtC50697), as well as a third gene (MENS cluster ID MtC00605). MtC30378 and MtC50697 were revealed also by microarray analysis of a cDNA library from mycorrhizal $M$. truncatula roots (Küster et al. 2004). Another Bcp gene specific for M. truncatula AM roots (AW584704, MtGI TC122470) was identified by a suppressive subtractive hybridization (SSH) experiment and realtime reverse-transcription polymerase chain reaction (RT-PCR) analysis (Wulf et al. 2003).

With transcriptome profiling of $M$. truncatula by microarrays, Hohnjec and associates (2005) identified two co-induced AM-specific MtBcp genes: TC133696 (MtGI code, original name TC87415) already identified by Journet and associates (2002) as MtC00605, and TC139394 (MtGI original name TC88539, labeled as $M t B c p 1)$, which seems to be identical to MtC30378. A $\beta$-glucuronidase (GUS) reporter gene construct with the AM-inducible promoter of MtBcpl (TC139394) showed that expression was prominent in arbusculated root regions and correlated with the intensity of AM colonization. Counterstaining of AM structures demonstrated that GUS expression was the strongest in the arbuscule-containing cells but was also present in adjacent cortical cells, although with less intensity. It was speculated that $B c p$ s might serve as mediators of electron transfer processes in the network of plastids in and around arbuscule-containing cells. The correlation between expression levels and arbuscular colonization intensity was also underlined by MtBcpl real-time PCR analyses in roots colonized by different AM fungal species (Feddermann et al. 2008). Differential expression of the other MtBcp (TC133696) in colonized roots also was indicated recently by the Affymetrix GeneChip Medicago Genome Array (Gomez et al. 2009).

A proteomic study, using two complementary mass spectrometry approaches and targeting the root plasma membrane (PM) fraction of noninoculated and AM-colonized M. truncatula, revealed MtBcpl (MENS cluster ID MtC30378) protein solely in AM roots (Valot et al. 2006). MtBcpl is a small protein (MW $12.5 \mathrm{kDa}$ ) with one copper-binding site and two hydrophobic domains at both the $\mathrm{N}$ - and $\mathrm{C}$-terminal regions. The first domain corresponds to a signal peptide and the second to a signal for glycosylphosphatidylinositol (GPI) anchoring at the PM extracellular surface. Very recently, localization of the MtBcp isoform TC139394 in plasma membrane of cortical cells harboring arbuscules and in the trunk region of periarbuscular membrane, as well as on perihyphal membrane within colonized cells, was demonstrated by Pumplin and Harrison (2009).

To better understand the relation between Bcps and AM colonization, we have studied AM-related MtBcps at the gene ex- pression level. We tested the hypotheses of their involvement in the development of AM symbiosis with a special emphasis on the level of arbuscular colonization. The expression levels of two highly AM-specific blue copper-binding proteins of the MtBcpl group (MENS cluster IDs MtC30378 and MtC50697) were studied by real-time quantitative PCR both i) during kinetic analyses of the wild-type $M$. truncatula Jemalong 5 (J5), either colonized or not with Glomus intraradices (DAOM181602), and ii) in different $M$. truncatula mutants at two time points (3 and 7 weeks after inoculation).

\section{RESULTS}

\section{Phylogenetic analysis and terminology of AM-specific MtBcps.}

In order to unravel sequence homologies and undoubtedly refer to AM-specific $M t B c p$ isoforms, we have created an amino-acid-based phylogenetic tree on the coding region of $M t B c p$ genes identified thus far using published sequences and homologous genes, with a special emphasis on AM- and symbiosis-specific ones (Fig. 1), and proposed an updated terminology for them (Supplementary Table 1). Using the recently available data of the various expression experiments performed with Medicago Genome Affymetrix chip (He et al. 2009), the expression level of the various $M t B c p$ s identified in this study could be presented in a large range of different plant tissues or interactions. The eight AM-specific MtBcps cluster together into two clearly separated neighboring groups, including those already characterized experimentally (Journet et al. 2002, Wulf et al. 2003, Küster et al. 2004), which we named MtBcpl, $M t B c p 2$, and MtBcp3. We named the MtBcpl isoforms MtBcpla (MENS ID MtC30378, MtGI TC139394) and MtBcplb (MENS ID MtC50697, no MtGI entry with identical sequence). $M t B c p 2$ and MtBcp3 contained only one gene-TC133696 and TC122470, respectively - the latter studied by Wulf and associates (2003). AM-specific MtBcp genes have, with the exception of TC127721, an intron of similar length (approximately 160 nucleotides) and all with a known localization are on chromosome 7, on the same BAC (AC126009) in close vicinity to each other.

\section{Colonization and growth.}

In the time-course experiment, mycorrhizal colonization increased continuously until the end of the growing period (Fig. 2). Most importantly, arbuscular colonization (A\%) of the root system (Fig. 2A) was also growing until the seventh week. Noninoculated plants had no colonization. Shoot/root fresh weight ratios (Supplementary Fig. 1) were significantly higher in mycorrhizal plants toward the end of the growing period.

AM colonization parameters ( $\mathrm{M} \%$ and $\mathrm{A} \%)$ showed a relation to the mutant genotype (Fig. 3). On the root surface of penetration defective mutants (TRV25-C and TRV25-D), only appressoria formation was detected; hypomycorrhizal TR25 and TR89 had intermediate colonization values, whereas the hypermycorrhizal TRV17 had the highest. TRV17 had similar levels of colonization at 3 and 7 weeks, though the other genotypes had increasing colonization parameters between the two time points. Vesicular colonization (V\%) of J5 and TRV17 genotypes were significantly different 3 weeks after colonization (23.3 and $50.1 \%$, respectively), whereas the difference was smaller at the second time point (21.3 and 40.6\%). Shoot/ root fresh weight ratios of the different genotypes showed a slight advantage for the AM plants at the 3-week-old stage (Supplementary Fig. 2). At 7 weeks, aerial parts of plants were already heavier than roots (shoot/root ratios $>1$ ), with a neat advantage to the TRV17 hypermycorrhizal mutant. 
TC129613

TC116896

TC121445

\section{Rhizobium specific}

TC119134

TC116361

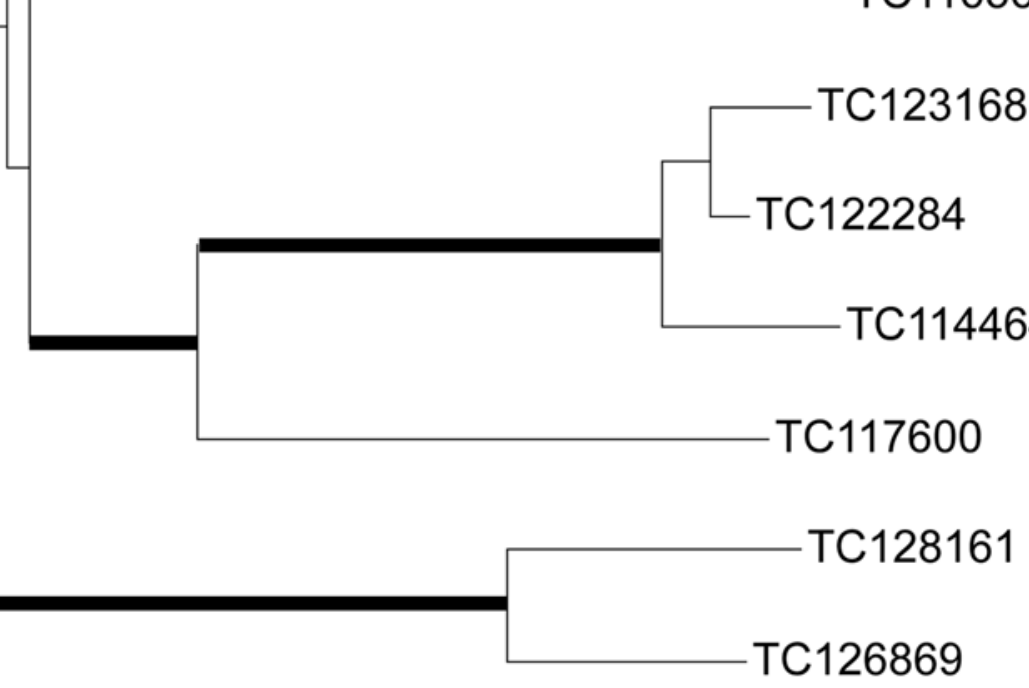

TC127721

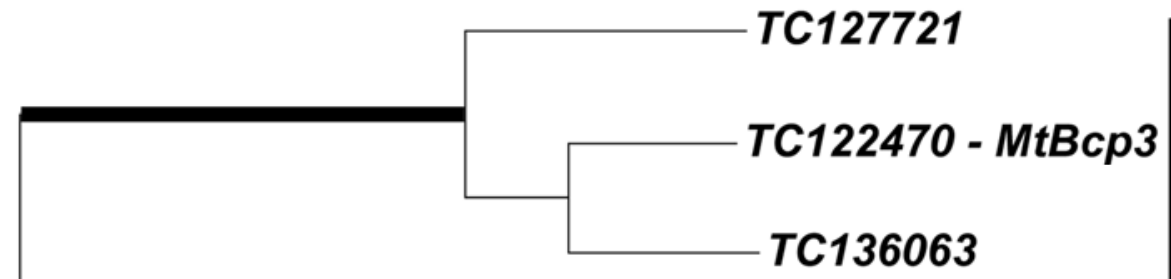

TC133696 - MtBcp2

TC129977

Mycorrhiza specific

Fig. 1. Phylogenetic tree (neighbor-joining) based on the complete amino acid sequences of the MtBcps specifically induced during the arbuscular mycorrhizal and Rhizobium symbiosis and their close homologs (according to the DFCI Medicago Gene Index, version 9.0). Mycorrhiza-specific MtBcp proteins published thus far are referred to by their codes proposed in the present study; other proteins are referred by their MtGI codes. Branches with bootstrap values higher than $98 \%$ are in bold. 


\section{Expression of AM-specific genes.}

Based on thorough genomic and proteomic characterization (Hohnjec et al. 2005; Valot et al. 2006; Feddermann et al. 2008), as well as their recent localization (Pumplin and Harrison 2009), MtBcpla (MtC30378) and the paralogous gene named MtBcplb (MtC50697) were selected for the gene expression studies as representatives of the paralogous AM-specific $M t B c p$ isogenes. The full coding region of $M t B c p l b$ was obtained from the original clone (MtBC05D06) in the present study. The polypeptide sequences of the two genes proved to be highly similar, with only three amino acids of difference (Supplementary Fig. 3). The expression pattern of the mycorrhizal-specific MtBcps were confirmed on the basis of the various Medicago Genome Affymetrix chips (He et al. 2009). Eight MtBcps were found to be induced specifically in mycorrhizal plants and only one in Rhizobium symbiosis (TC121445). No pathogen or elicitor specificity was identified among the studied $M t B c p$ genes.

The time-course experiment showed that expression of all three AM-specific genes investigated displayed a gradual increase as plants grew older (Fig. 4). Regression curves show (Fig. 5) that a correlation could be established between the relative expression values and arbuscular colonization. However, in the case of MtPT4, this correlation was not as strong as with the blue copper-binding genes.

After establishing the kinetic response of expression of AMspecific genes, a second experiment was set up to compare several mutants, either hypo- or hypermycorrhizal, to the reference wild-type J5 used above for the time-course experiment. Similarly to the preceding experiment, all three genes showed a reduced expression in the hypomycorrhizal genotypes compared with J5 at both time points (Fig. 6). Three weeks after colonization, expression of MtPT4 was higher in TRV17 than in J5 whereas the differences disappeared by the seventh week. Expression of both MtBcpl genes in TRV17 showed an increase only at the seventh week (Fig. 6). No expression of any of the three genes was detected in the two penetration-defective mutants.

\section{DISCUSSION}

In the present work, we studied the expression of two strictly arbuscular mycorrhiza-related blue copper-binding proteins of M. truncatula: MtBcpla and MtBcplb (MENS cluster IDs MtC30378 and MtC50697). First, a time-course experiment was set up to characterize the kinetic changes of expression in parallel to colonization from 1 to 7 weeks in wild-type $M$. truncatula J5 plants. Complementary to this, in a second experiment, we used $M$. truncatula colonization mutants described by Morandi and associates $(2000,2005)$ together with $\mathrm{J} 5$ as a control to further clarify the possible relationship between mycorrhizal colonization and transcription of $M t B c p l$ genes. In parallel, MtPT4, a well-described AM-specific phosphate transporter located in the periarbuscular membrane (Harrison et al. 2002; Javot et al. 2007) was also investigated, as an internal control for arbuscular-localized genes, providing a valuable tool to evaluate AM-specific gene expression.

The continuous increase of colonization (Fig. 2) of mycorrhizal plants in the time-course experiment showed an active and undisrupted process of symbiosis and a considerable colonizing potential also at the end of the growth period. Colonization parameters of the mutant plants reflected the differences in genotypes, because the process of colonization was hindered in hypomycorrhizal mutants and increased in the hypermycorrhizal TRV17 compared with the wild-type control J5 (Fig. 3). Arbuscular colonization of TRV17 was already very high (over $80 \%$ ) at the third week and did not change at the seventh week compared with the mycorrhizal data of J5 corresponding to both types of experiments (kinetic and effect of the genetic background). TRV17 roots were colonized faster and reached a plateau of the colonization process much earlier whereas, in the other genotypes, the fungal partner still had growth potential at the second harvest time. This phenomenon might also be correlated with the smaller root fresh weights of colonized TRV17 providing less space for the fungal growth (Morandi et al. 2000), combined with the high intraradical, including vesicular colonization potential of the $G$. intraradices strain used (Plenchette and Strullu 2003). Indeed, the number of vesicles was consistently higher in TRV17 mutants compared with the J5 plants at both time points, indicating that not only the speed of colonization but also its subsequent developmental stage was accelerated. TRV17 plants represent the sunn-4 mutation of the $S U N N$ gene leading to hypernodulation and reduced root growth due to the lack of negative feedback on the development of nodules (Schnabel et al. 2005), and it would not be surprising that some sort of autoregulation of the AM process also occurs.

Shoot/root ratios of the time-course experiment mirrored the typical effect of mycorrhizal colonization on the physiology and growth of plants. In the mutant experiment, shoot/root ratios of TRV17 were always the highest due to the lower root fresh weights typical of this mutant (data not shown). Shoot/ root ratios of the penetration-defective and hypomycorrhizal mutants were somewhat smaller at the third week than those of the J5 controls whereas they were all similar at the seventh week, regardless of the differences in colonization parameters. The colonization process was interrupted at different developmental stages in the mutant genotypes, leading to zero or reduced colonization rates (Morandi et al. 2000, 2005). However, AM fungi were still active even in the seventh week, as

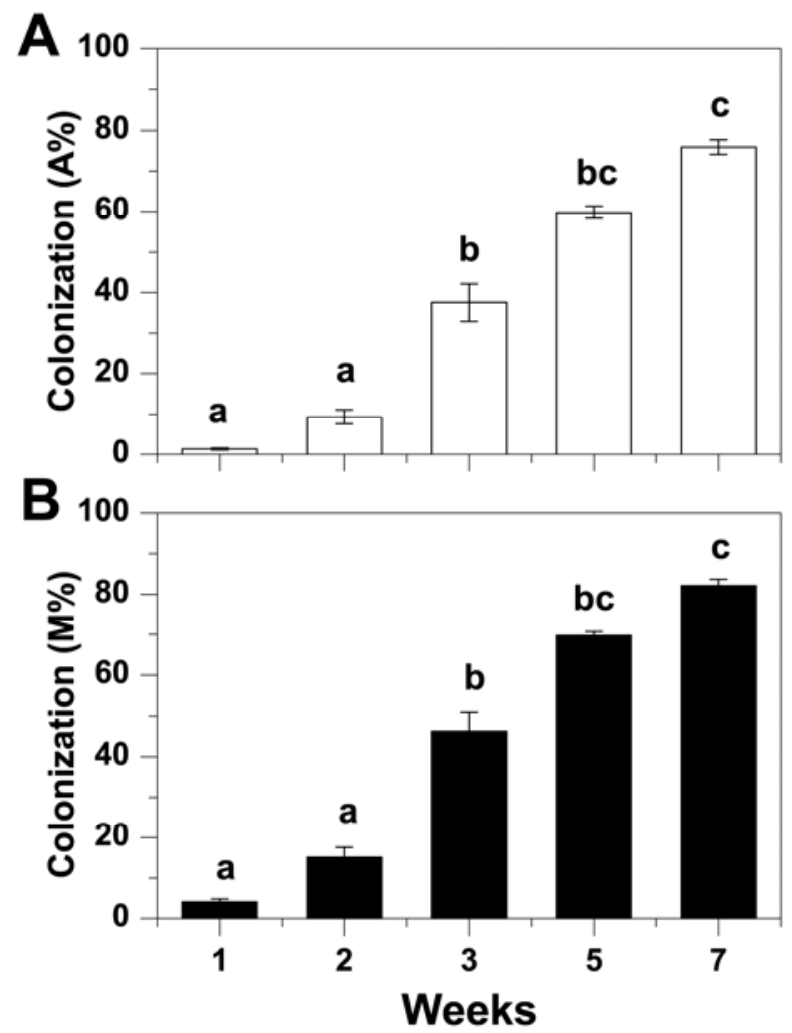

Fig. 2. Colonization parameters of the wild-type Medicago truncatula Jemalong 5 in the time course experiment from 1 to 7 weeks after inoculation with Glomus intraradices DAOM 181602, determined according to Trouvelot and associates (1986). A, Arbuscular colonization and B, total (hyphal) colonization. Means followed by different letters were significantly different at $P<0.05$. Error bars represent standard error $(n=4)$. 
indicated by the growing colonization intensities in TR25 and TR89 and the fungal appressoria (data not shown) on the surface of TRV25-C and TRV25-D roots.

MtBcpla was first characterized by nontargeted approaches at both genomic (Journet et al. 2002; Küster et al. 2004) and proteomic (Valot et al. 2006) levels. Although other forms of $M t B c p s$ were also indicated by these studies, targeted studies focused only on MtBcpla. It was first localized mainly in the arbuscule-containing cells and with lower abundance within adjacent cortical cells by a GUS fusion to its promoter (Hohnjec et al. 2005), while Pumplin and Harrison (2009) located it more precisely by fluorescent live-cell imaging in the plasma membrane of cortical cells with arbuscules and adjacent to fungal hyphae, as well as on the periarbuscular membrane around the trunks. However, it was not present around the branches of the midsize or mature arbuscules, where, in contrast, MtPT4 was located. An apparent correlation of expression of MtBcpla to arbuscular colonization intensity was shown by Feddermann and associates (2008). However, they did not consider the high similarity of $M t B c p l$ genes, whereby primers used in previous investigations targeted almost identical coding regions and did not discriminate between paralogous $M t B c p l$ genes. For the present research, we designed selective primers targeted on the more specific $3^{\prime}$ noncoding regions of both $M t B c p l$ genes: $M t B c p l a$ and $M t B c p l b$.

MtPT4 is located on the periarbuscular membrane (Harrison et al. 2002; Pumplin and Harrison 2009) and has a fundamen- tal role in AM symbiosis (Javot et al. 2007). The steady increase of its expression levels during plant growth (Fig. 4), which correlates also with the number of arbuscules (Figs. 2 and 5), indicates the normal functioning of the symbiotic membrane. Kinetics of both MtBcpla and MtBcplb mRNAs were similar, with a continuous increase, like that of MtPT4 (Fig. 4), although a stronger correlation to arbuscular colonization was observed for the two MtBcpl genes (Fig. 5). Considering the opposed localization of MtBcpla and MtPT4 in different membrane domains (Pumplin and Harrison 2009), it is intriguing to speculate that the high level of correlation might refer to a basal role of MtBcpla in arbuscule development or functioning, where the protein needs to be in a constant ratio. In contrast, the amount of MtPT4 may be related to other factors depending on the intensity of the transport processes through the periarbuscular membrane.

It seems that induction levels of certain $M t B c p$ genes may be fungal specific. Although MtBcp2 (MtC00605) was relatively highly induced in roots colonized with $G$. intraradices or $G$. mosseae (Hohnjec et al. 2005; Gomez et al. 2009), induction was variable regarding MtBcpla expression. Feddermann and associates (2008) showed a lower MtBcpla expression level in a symbiosis formed by Scutellospora castanea then the two Glomus spp. mentioned before. Grunwald and associates (2009) found a low induction level of MtBcplb (MtC50697) in roots colonized with $G$. intraradices, whereas it was higher with Gigaspora rosea. Despite the differences in experimental
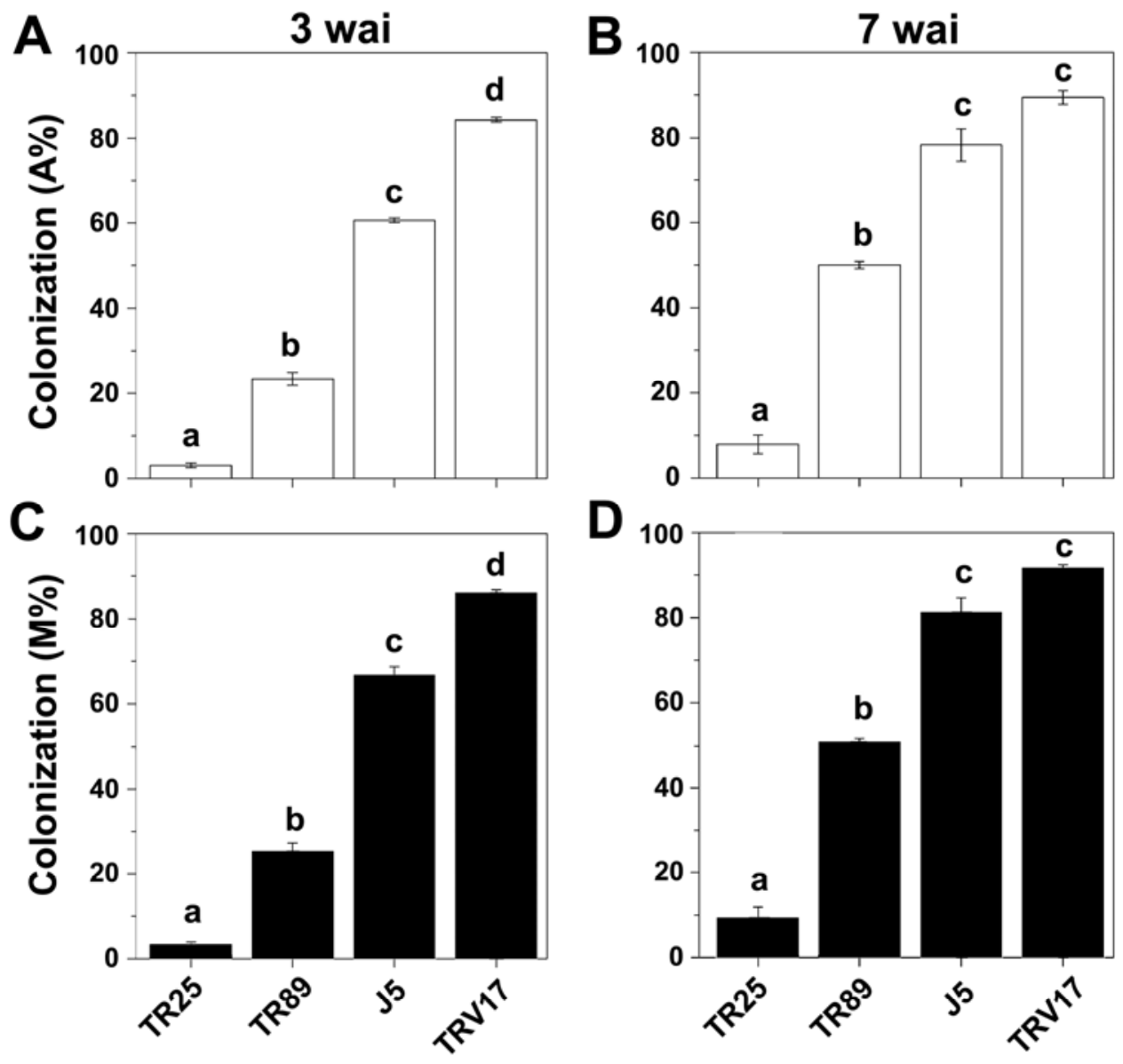

Genotypes

\section{Genotypes}

Fig. 3. Colonization parameters of the wild-type Medicago truncatula Jemalong 5 and the different mutants at 3 and 7 weeks after inoculation (wai) with Glomus intraradices DAOM 181602, determined according to Trouvelot and associates (1986). TRV25-C and D were not colonized; therefore, they are not presented. A, Arbuscular colonization of plants 3 wai; $\mathbf{B}$, Arbuscular colonization of plants 7 wai; $\mathbf{C}$, total (hyphal) colonization 3 wai; D, total (hyphal) colonization 7 wai. Means followed by different letters were significantly different at $P<0.05$. Error bars represent standard error $(n=3)$. 
conditions, this might be parallel to the findings of the present experiment, where expression of $M t B c p l b$ proved to be lower by approximately one order of magnitude than that of MtBcpla (Fig. 4). These differences in the expression level could not be detected with the Medicago Genome Affymetrix chip (He et al. 2009), because MtBcpla, MtBcplb, TC132480, and TC129977 could not be differentiated due to their sequence similarity.

A similar trend in expression levels compared with colonization intensities was also observed in the two mutant experiments we performed, because expression of all three genes studied was much lower in hypomycorrhizal genotypes than in J5 (Fig. 6), whereas no expression was detected in the two lines of penetration-defective mutants (data not shown). As projected from the arbuscule abundance, TRV17 had an increased MtPT4 level 3 weeks after colonization. At the seventh week, however, expressions of MtPT4 in TRV17 and J5 were
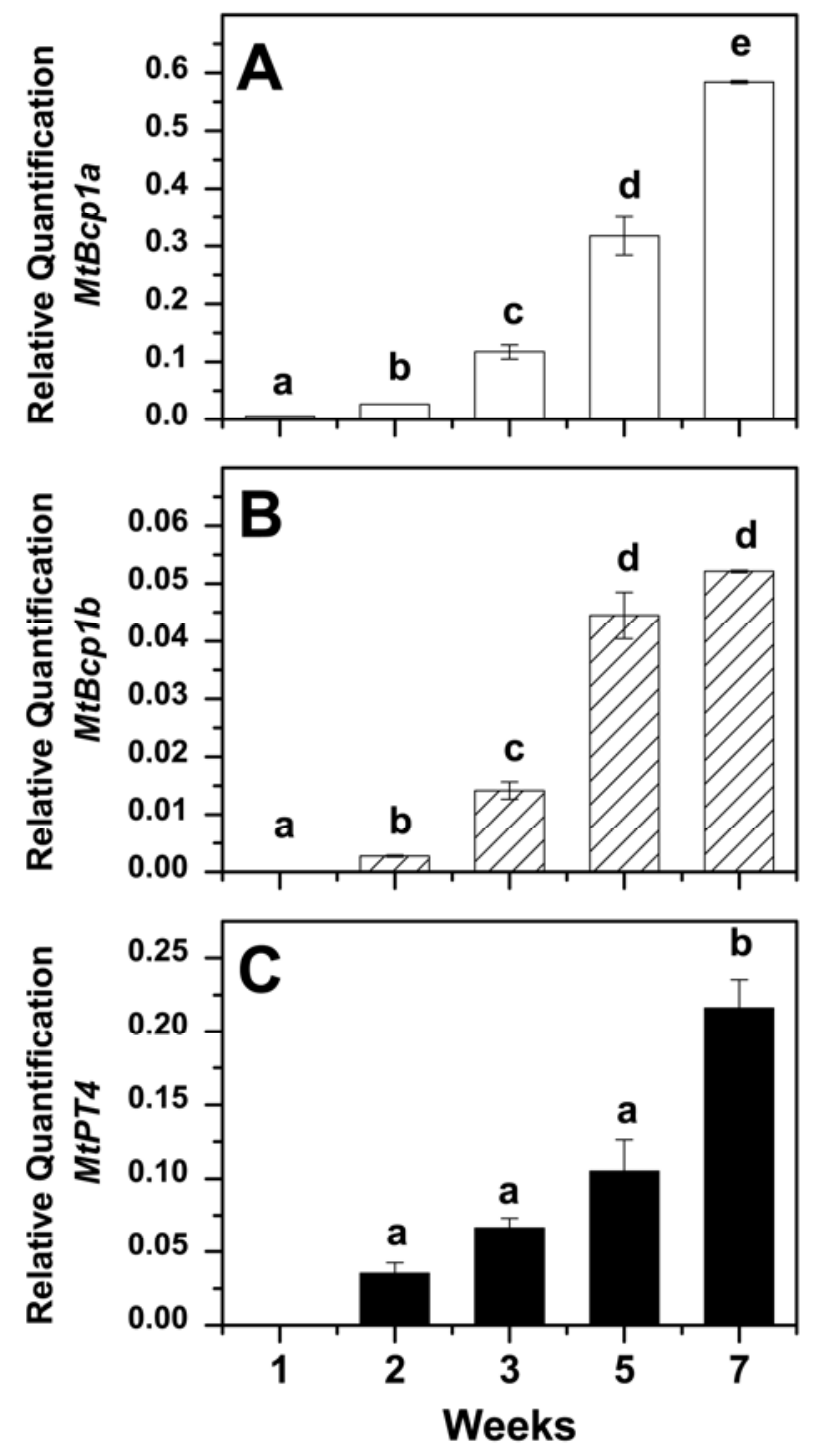

Fig. 4. Gene expression profiling by quantitative reverse-transcription polymerase chain reaction of $\mathbf{A}, M t B c p l a ; \mathbf{B}, M t B c p 1 b$; and $\mathbf{C}, M t P T 4$ genes. Experiments were carried out on RNAs extracted from roots of Medicago truncatula wild-type Jemalong 5 from 1 to 7 weeks after inoculation with Glomus intraradices DAOM 181602. Transcript levels were quantified relative to the constitutively expressed EIF5A2 gene. Data are expressed in arbitrary units (AU). Means followed by different letters were significantly different $(P<0.05)$. Error bars represent standard error $(n=4$, with two technical repeats). comparable, indicating that, above a certain level of colonization, expression values may reach a threshold phase, as observed also in the time-course experiment (Fig. 5).

Expression of MtBcpla and MtBcplb genes in TRV17 could not be directly related to arbuscule levels (Fig. 6). The high arbuscular and vesicular colonization levels in TRV17 already at the third week may refer to a different developmental stage of the symbiosis compared with the wild-type control, where arbuscular colonization and expression of genes with a symbiotic function do not relate directly to the developmental age of the symbiosis and may be the function of other (e.g., environmental) factors as well.

\section{Conclusions.}

The present work reports the first study on the time-course expression of two paralogous $M t B c p l$ genes and on their presence in different genetic backgrounds of $M$. truncatula. In addition to previous studies hypothesizing a direct role of the MtBcpla gene in arbuscule functioning (Hohnjec et al. 2005; Valot et al. 2006), which was also supported by the localization of $M t B c p 1$ a on plant PM surrounding fungal hyphae and arbuscular trunks (Pumplin and Harrison 2009), we clearly established a solid correlation between expressions of both $M t B c p l$ isoforms and arbuscular colonization during a relatively long time frame. The results indicate that MtBcpla and
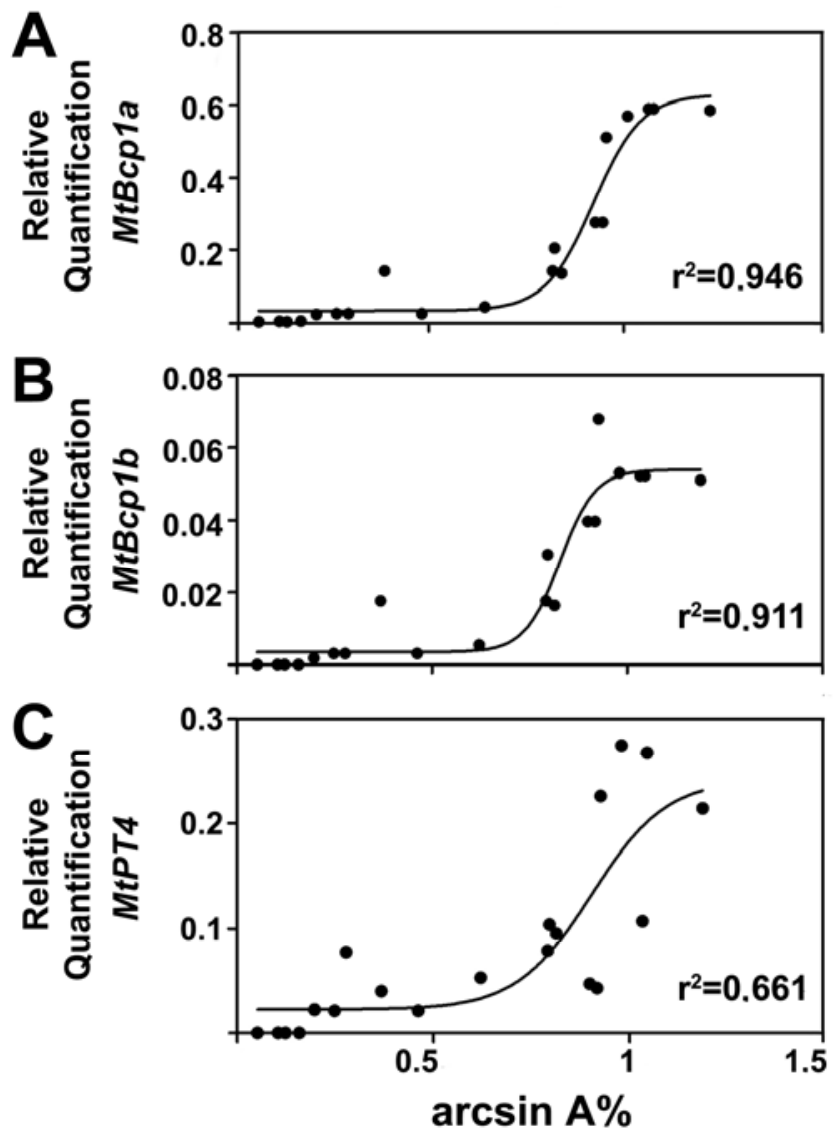

Fig. 5. Sigmoidal regression curves for expression (relative quantification compared with EIF5A2 expression) of A, MtBcpla; $\mathbf{B}, M t B c p 1 b$; and $\mathbf{C}$, $M t P T 4$ genes against arbuscular colonization values ( $\arcsin$ transformed). Curves were fitted using the equation $Y=$ Bottom $+($ Top - Bottom $) /(1+$ $10 \times[(\operatorname{LogEC} 50-X) \times$ HillSlope $])$. Coefficients of determination $\left(r^{2}\right)$ are shown on the figures. Experiments were carried out on RNAs extracted from roots of Medicago truncatula wild-type Jemalong 5 from 1 to 7 weeks after inoculation with Glomus intraradices DAOM 181602. Arbuscular colonization parameters were determined according to Trouvelot and associates (1986). 
$M t B c p 1 b$ may well have a fundamental function in the symbiotic interaction; however, their exact role is still unknown. Based on the recent localization of MtBcpla (Pumplin and Harrison 2009), as well as its predicted posttranslational modification with a GPI moiety (Valot et al. 2006), the hypothesis regarding their function in electron transfer processes in the network of plastids surrounding arbuscules as proposed by Hohnjec and associates (2005) is not confirmed. GPIanchored proteins were shown to be concentrated in specific plasma membrane regions called detergent-resistant membranes (DRM) or "lipid rafts" (Simons and Ikonen 1997; Bhat and Panstruga 2005). Proteins localized in DRM can act in signal transduction processes (Simons and Toomre 2000), cytoskeleton organization (Falk et al. 2004), regulation of exocytosis (Salaün et al. 2004) and apoptosis (Garcia et al. 2003) signals for pathogen entry (Rosenberger et al. 2000), as well as plant innate immunity (Fujiwara et al. 2009). Based on the morphological similarities between arbuscules and haustoria of biotrophic pathogens, Pumplin and Harrison (2009) already underlined the homologous pattern also in the localization of plasma membrane markers, such as MtBcp 1a in AM-colonized cells. Therefore, it would not be surprising if GPI-anchored blue copper-binding proteins would be located in DRM responsible for an as-yet-uncharacterized function in the AM symbiosis requiring a polarized subcellular localization, possibly related to arbuscule biogenesis. The RNAi constructs we are presently handling will be a valuable tool for helping to assign a role to $M t B c p$-related proteins in the development and functioning of the AM symbiosis. Concerning the stronger correlation of $M t B c p l$ isoforms to arbuscular colonization than in the case of MtPT4, they may be considered a new and more efficient molecular marker of the AM symbiotic development.

\section{MATERIALS AND METHODS}

Plant material.

In this work, the M. truncatula wild-type J5 and the following mutants were tested: TR25 and TR89 $\left(\mathrm{Nod}^{ \pm} \mathrm{Myc}^{ \pm}\right)$, described by Sagan and associates (1995) and Morandi and associates (2005), which were ascribed to gene Dmi2/Mtsym 2 coding a nodulation receptor kinase (Endre et al. 2002); TRV17 $\left(\mathrm{Myc}^{++}\right.$ $\mathrm{Nod}^{++}$), a hypermycorrhizal mutant described by Morandi and associates (2000) ascribed to gene sunn; Mtsym12 (Schnabel et al. 2005); and TRV25-C and TRV25-D, two strictly defective mutants for symbioses ( $\left.\mathrm{Nod}^{-} \mathrm{Myc}^{-}\right)$(dmi3, Mtsym 13), coding a nuclear calcium/calmodulin-dependent protein kinase (Lévy et al. 2004; Mitra et al. 2004; Oldroyd and Downie 2006). These two mutants are two sublines of a previously described mutant, TRV25 (Morandi et al. 2005), differing in the presence of a coumestrol conjugate in roots of TRV25-C but absent from TRV25-D (D. Morandi, unpublished data).

Inoculation, plant growth, and harvest of plants.

Seed of M. truncatula plants were scarified and surface sterilized. After a 3-day-long vernalization period in darkness at $4{ }^{\circ} \mathrm{C}$, they were germinated on $0.7 \%$ sterile agar, then placed into $75 \mathrm{ml}$ of sterile mix (2:1) of Terragreen (Agsorb; Oil Dry Corporation, IMC Imcore, Chicago) and Epoisses clay soil (neutral clay loam). Inoculum of Glomus intraradices N. C. Schenck \& G. S. Smith (DAOM 181602) was mixed with soil media before planting. Control plants were inoculated with heat-sterilized inoculum. The inoculum consisted of hyphae, spores, and root fragments and was propagated on Allium porrum. Plants were grown under controlled conditions $(420 \mu \mathrm{E}$ $\mathrm{m}^{-2} \mathrm{~s}^{-1}$ for $16 \mathrm{~h}$ of light; 24 and $19^{\circ} \mathrm{C}$ day and night tempera-
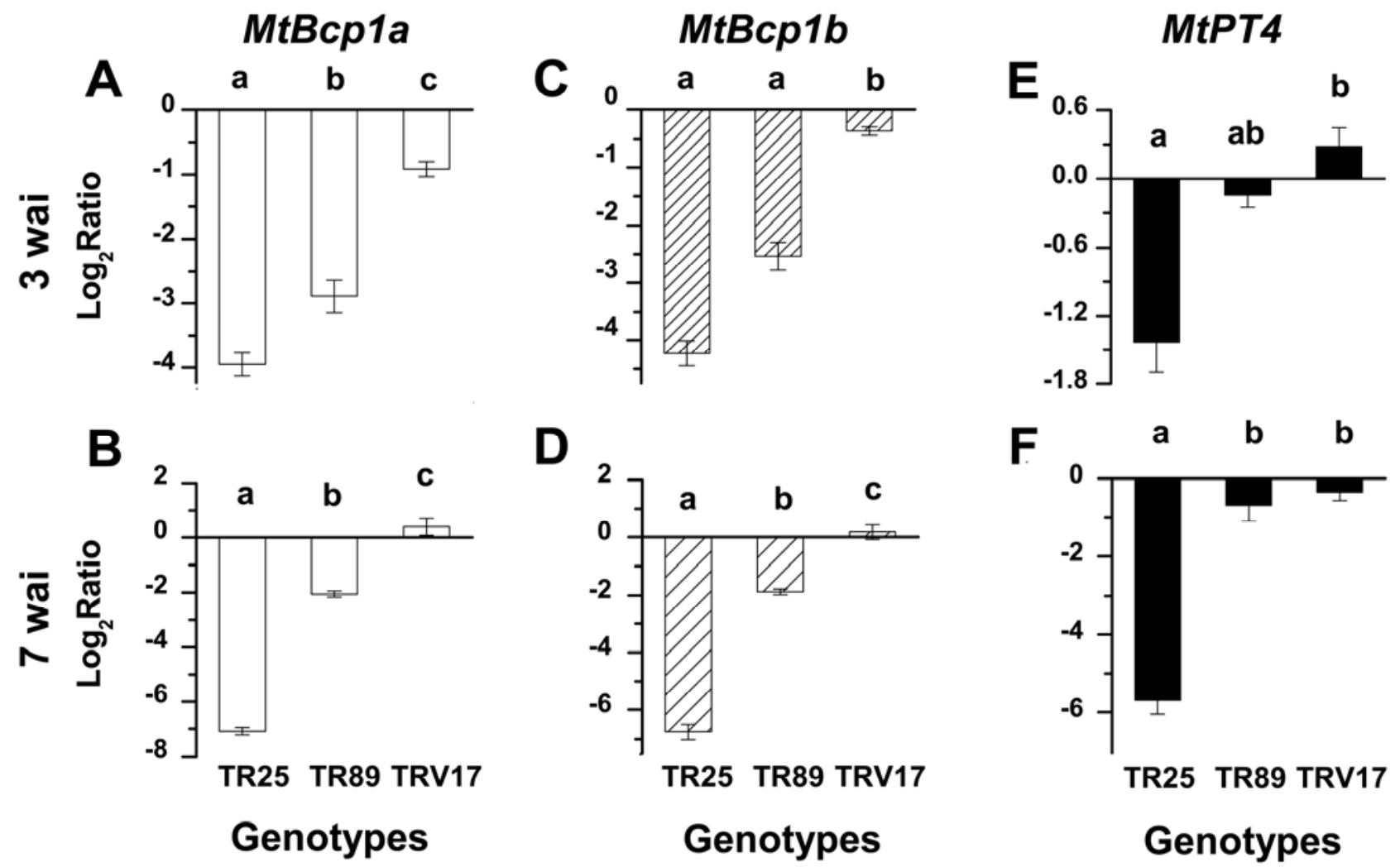

Fig. 6. Gene expression profiling by quantitative reverse-transcription polymerase chain reaction of $\mathbf{A}$ and $\mathbf{B}$, $M t B c p l a$ gene 3 and 7 weeks after inoculation (wai); C and D, MtBcplb gene 3 and 7 wai; and $\mathbf{E}$ and F, MtPT4 gene 3 and 7 wai. Experiments were carried out on RNAs extracted from roots of Medicago truncatula wild-type Jemalong 5 and the different mutants at 3 and 7 wai with Glomus intraradices DAOM 181602. Transcript levels were quantified relative to the constitutively expressed EIF5A2 gene and expressed as a $\log _{2}$ ratio compared with the level of transcription in J5 control. Means followed by different letters were significantly different $(P<0.05)$. Error bars represent standard error $(n=3$, with two technical repeats). 
tures, respectively; 60\% humidity) and watered twice a week with a modified Long Ashton nutrient solution (Hewitt 1966) ( $2 \times$ the $\mathrm{KNO}_{3},{ }_{1}^{1} / 10$ of the $\mathrm{NaH}_{2} \mathrm{PO}_{4}$ ) and distilled water on the other days. Control and inoculated plants were placed randomly and treated identically. At harvest, plants were removed from pots, gently rinsed with tap water and deionized water, and dried with paper towels. Plants were separated into shoots and roots and weighed directly. Root portions for molecular analyses were frozen immediately in liquid $\mathrm{N}_{2}$, then stored at $-80^{\circ} \mathrm{C}$.

In all cases, two parallel experiments were performed which gave comparable results; therefore, only one of them is shown. The kinetic experiments included four biological replicates (plants) of 1-, 2-, 3-, 5-, and 7-week-old wild-type M. truncatula $\mathrm{J} 5$ plants. Three biological replicates were used in mutant experiments with two time points per treatment ( 3 and 7 weeks after inoculation).

\section{Analysis of colonization.}

Roots were stained with the ink-vinegar method (Vierheilig et al. 1998). Assessment of colonization was done according to Trouvelot and associates (1986) calculated with the Mycocalc program.

\section{Molecular analyses.}

Total RNA from roots was isolated using the RNeasy Kit (Qiagen, Hilden, Germany) according to the manufacturers' instructions and eluted in RNAse-free water. Genomic DNA was eliminated by the RQ1 DNase enzyme (Promega Corp., Madison, WI, U.S.A.). DNase-treated RNA mix was checked by PCR to exclude genomic DNA contamination. RNA concentration was quantified by a Qubit fluorometer (Invitrogen, Carlsbad, CA, U.S.A.). RT reaction was performed by the MMLV reverse transcriptase (Promega Corp.) according to the manufacturer's instructions. Amount of mRNA was quantified by quantitative real-time PCR reaction using Absolute SYBR green ROX Mix (Thermo Scientific, Waltham, MA, U.S.A.) and an ABI Prism 7900HT Sequence Detection System (Applied Biosystems, Foster City, CA, U.S.A.).

qPCR reactions, containing $10 \mu$ of $2 \times$ SYBR Green ROX mix, $5 \mu \mathrm{l}$ of cDNA, and $100 \mathrm{nM}$ each gene-specific primer in a final volume of $20 \mu \mathrm{l}$, were incubated at: $95^{\circ} \mathrm{C}$ for $15 \mathrm{~min}$ and 50 cycles of $93^{\circ} \mathrm{C}$ for $15 \mathrm{~s}, 60^{\circ} \mathrm{C}$ for $30 \mathrm{~s}$, and $72^{\circ} \mathrm{C}$ for $30 \mathrm{~s}$. Immediately after thermal cycling, a dissociation curve was performed by heating PCR products from 60 to $95^{\circ} \mathrm{C}$ to reveal the presence of nonspecific amplicons, including primer dimerization. Data were analyzed using the SDS 2.3 software (Applied Biosystems). All amplification plots were analyzed with a threshold of 0.3 to obtain cycle threshold values. No-template and non-reverse transcribed samples were included as negative controls for each primer pair. Standard curves were generated by all primer pairs on serial dilutions. Real-time PCR efficiencies derived from standard curves were checked to be between 90 and $110 \%$.

Eukaryotic translation initiation factor 5A2 (eiF5A2, TC76568) was used for a constitutively expressed control gene (Gallardo et al. 2007). In addition to the two MtBcpl genes, $M$. truncatula phosphate transporter gene MtPT4 was also tested using the primers MtPT4_For (TGC GAT GAC TTA CTA CTG G) and MtPT4_Rev (TGA CGA ATA AGT CCC ATT GC). $M t B c p l$ primers used in earlier studies did not separate the two homologous genes MtBcpla and MtBcplb (MENS cluster IDs MtC30378 and MtC50697) because of the high level of similarity in the coding region. Therefore, more selective primers were designed. Primer MtBcp1a+b_F (TGG TAT GTT TGT GGA GTT GC) was annealing in the coding region of both $M t B c p l$ genes; however, reverse primers were annealing in the $3^{\prime}$ noncoding region of the cDNA. Reverse primers were MtBcpla_R (GAT TTG AAA GAA CTC ATG CAC) and MtBcp1b_R (AGT GAG AGT TAC AAT TTG AAT AC) for $M t B c p l a$ and $M t B c p l b$, respectively.

The sequence of MtBcplb (MENS cluster ID MtC50697) was not complete; therefore, the original clone, MtBC05D06, was sequenced. The sequence was deposited in GenBank with the accession number FN600697.

\section{Phylogenetic analysis.}

The complete amino acid sequences (154 amino acids) of the MtBcps specifically induced during the AM or Rhizobium symbiosis were aligned with homologous sequences (as a result of a similarity search of DFCI Medicago Gene Index version 9.0, E value <2.6e-14) using Clustal X 2.0. Phylogenetic analysis was performed using the neighbor-joining (NJ) algorithm, avoiding the position with gaps. The reliability of the internal branches of the NJ tree was assessed using the bootstrap method with 1,000 replicates. The tree was drawn using NJplot.

\section{Statistical analysis.}

Colonization data were arcsin transformed before statistical analysis. Results were analyzed by Student's $t$ test or analysis of variance followed by a Tukey post hoc test using the SPSS 7.5 statistical software. Linear regression was done by the Graph Pad Prism statistics program (GraphPad Software Inc., San Diego, CA, U.S.A.).

\section{ACKNOWLEDGMENTS}

This work was supported by the Department of SPE, INRA, France and the Burgundy Council (CT 06516 CP 015 S248). I. Parádi was supported by a grant from the Burgundy Council (CRB no. 07 HCP 37). We thank O. Chatagnier and D. Bru for their invaluable help with the laboratory work.

\section{LITERATURE CITED}

Alexander, T., Meier, R., Toth, R., and Weber, H. C. 1988. Dynamics of arbuscule development and degeneration in mycorrhizas of Triticum aestivum L. and Avena sativa $\mathrm{L}$. with reference to Zea mays L. New Phytol. 110:363-370.

Bhat, R. A., and Panstruga, R. 2005. Lipid rafts in plants. Planta 223:5-19.

Bonfante, P., and Genre, A. 2008. Plants and arbuscular mycorrhizal fungi: An evolutionary-developmental perspective. Trends Plant Sci. 13:492498.

Dexheimer, J., Marx, C., Gianinazzi-Pearson, V., and Gianinazzi, S. 1985. Ultracytological studies on plasmalemma formations produced by host and fungus in vesicular-arbuscular mycorrhizae. Cytologia 50:461-471.

Endre, G., Kereszt, A., Kevei, Z., Mihacea, S., Kalo, P., and Kiss, G. B. 2002. A receptor kinase gene regulating symbiotic nodule development. Nature 417:962-966.

Falk, J., Thoumine, O., Dequidt, C., Choquet, D., and Faivre-Sarrailh, C. 2004. NrCAM coupling to the cytoskeleton depends on multiple protein domains and partitioning into lipid rafts. Mol. Biol. Cell 15:46954709 .

Feddermann, N., Boller, T., Salzer, P., Elfstrand, S., Wiemken, A., and Elfstrand, M. 2008. Medicago truncatula shows distinct patterns of mycorrhiza-related gene expression after inoculation with three different arbuscular mycorrhizal fungi. Planta 227:671-680.

Fester, T., Strack, D., and Hause, B. 2001. Reorganization of tobacco root plastids during arbuscule development. Planta 213:864-868.

Fujiwara, M., Hamada, S., Hiratsuka, M., Fukao, Y., Kawasaki, T., and Shimamoto, K. 2009. Proteome analysis of detergent-resistant membranes (DRMs) associated with OsRac1-mediated innate immunity in rice. Plant Cell Physiol. 50:1191-1200.

Gallardo, K., Firnhaber, C., Zuber, H., Hericher, D., Belghazi, M., Henry, C., Kuster, H., and Thompson, R. 2007. A combined proteome and transcriptome analysis of developing Medicago truncatula seeds: Evidence for metabolic specialization of maternal and filial tissues. Mol. Cell Prot. 6:2165-2179.

Garcia, A., Cayla, X., Fleischer, A., Guergnon, J., Canas, F. A. F., Rebollo, M. P., Roncal, F., and Rebollo, A. 2003. Rafts: A simple way to control apoptosis by subcellular redistribution. Biochimie 85:727-731. 
Genre, A., and Bonfante, P. 1998. Actin versus tubulin configuration in arbuscule-containing cells from mycorrhizal tobacco roots. New Phytol. 140:745-752.

Gianinazzi-Pearson, V. 1996. Plant cell responses to arbuscular mycorrhizal fungi: Getting to the roots of the symbiosis. Plant Cell 8:1871-1883.

Gomez, S. K., Javot, H., Deewatthanawong, P., Torres-Jerez, I., Tang, Y., Blancaflor, E. B., Udvardi, M. K., and Harrison, M. J. 2009. Medicago truncatula and Glomus intraradices gene expression in cortical cells harboring arbuscules in the arbuscular mycorrhizal symbiosis. BMC Plant Biol. 9:10.

Grunwald, U., Nyamsuren, O., Tarnasloukht, M., Lapopin, L., Becker, A. Mann, P., Gianinazzi-Pearson, V., Krajinski, F., and Franken, P. 2004. Identification of mycorrhiza-regulated genes with arbuscule development-related expression profile. Plant Mol. Biol. 55:553-566.

Grunwald, U., Guo, W., Fischer, K., Isayenkov, S., Ludwig-Müller, J. Hause, B., Yan, X., Küster, H., and Franken, P. 2009. Overlapping expression patterns and differential transcript levels of phosphate transporter genes in arbuscular mycorrhizal, Pi-fertilized and phytohormonetreated Medicago truncatula roots. Planta 229:1023-1034.

Harrison, M. J., Dewbre, G. R., and Jinyuan, L. 2002. A phosphate transporter from Medicago truncatula involved in the acquisition of phosphate released by arbuscular mycorrhizal fungi. Plant Cell 14:24132429.

He, J., Benedito, V. A., Wang, M., Murray, J. D., Zhao, P. X., Tang, Y., and Udvardi, M. K. 2009. The Medicago truncatula gene expression atlas web server. BMC Bioinf. 10:441-449.

Hewitt, E. J. 1966. Sand and Water Culture Methods used in the Studies of Plant Nutrition. Tech. Commun. 22. Commonwealth Agricultural Bureau, London.

Hohnjec, N., Vieweg, M. F., Pühler, A., Becker, A., and Küster, H. 2005. Overlaps in the transcriptional profiles of Medicago truncatula roots inoculated with two different Glomus fungi provide insights into the genetic program activated during arbuscular mycorrhiza. Plant Physiol. 137:1283-1301.

Javot, H., Penmetsa, R. V., Terzaghi, N., Cook, D. R., and Harrison, M. J 2007. A Medicago truncatula phosphate transporter indispensable for the arbuscular mycorrhizal symbiosis. Proc. Natl. Acad. Sci. U.S.A. 104:1720-1725.

Journet, E. P., van Tuinen, D., Gouzy, J., Crespeau, H., Carreau, V., Farmer, M. J., Niebel, A., Schiex, T., Jaillon, O., Chatagnier, O., Godiard, L., Micheli, F., Kahn, D., Gianinazzi-Pearson, V., and Gamas, P. 2002. Exploring root symbiotic programs in the model legume Medicago truncatula using EST analysis. Nucleic Acid Res. 30:5579-5592.

Küster, H., Hohnjec, N., Krajinski, F., El, Y. F., Manthey, K., Gouzy, J., Dondrup, M., Meyer, F., Kalinowski, J., Brechenmacher, L., van Tuinen, D., Gianinazzi-Pearson, V., Pühler, A., Gamas, P., and Becker, A. 2004. Construction and validation of cDNA-based Mt6k-RIT macroand microarrays to explore root endosymbioses in the model legume Medicago truncatula. J. Biotechnol. 108:95-113.

Lévy, J., Bres, C., Geurts, R., Chalhoub, B., Kulikova, O., Duc, G., Journet, E.-P., Ané, J.-M., Lauber, E., Bisseling, T., Dénarié, J., Rosenberg, C., and Debellé, F. 2004. A putative Ca2+ and calmodulin-dependent protein kinase required for bacterial and fungal symbioses. Science 303:1361-1364.

Liu, J. Y., Blaylock, L. A., Endre, G., Cho, J., Town, C. D., VandenBosch, K. A., and Harrison, M. J. 2003. Transcript profiling coupled with spatial expression analyses reveals genes involved in distinct developmental stages of an arbuscular mycorrhizal symbiosis. Plant Cell 15:21062123

Mitra, R. M., Gleason, C. A., Edwards, A., Hadfield, J., Downie, J. A., Oldroyd, G. E. D., and Long, S. R. 2004. A Ca ${ }^{2+} /$ calmodulin-dependent protein kinase required for symbiotic nodule development: Gene identification by transcript-based cloning. Proc. Natl. Acad. Sci. U.S.A. 101:4701-4705.

Morandi, D., Sagan, M., Prado-Vivant, E., and Duc, G. 2000. Influence of genes determining supernodulation on root colonization by the mycor- rhizal fungus Glomus mosseae in Pisum sativum and Medicago truncatula mutants. Mycorrhiza 10:37-42.

Morandi, D., Prado, E., Sagan, M., and Duc, G. 2005. Characterisation of new symbiotic Medicago truncatula (Gaertn.) mutants, and phenotypic or genotypic complementary information on previously described mutants. Mycorrhiza 15:283-289.

Nakamura, K., and Go, N. 2005. Function and molecular evolution of multicopper blue proteins. Cell Mol. Life Sci. 62:2050-2066.

Oldroyd, G. E. D., and Downie, J. A. 2006. Nuclear calcium changes at the core of symbiosis signalling. Curr. Opin. Plant Biol. 9:351-357.

Plenchette, C., and Strullu, D. G. 2003. Long-term viability and infectivity of intraradical forms of Glomus intraradices vesicles encapsulated in alginate beads. Mycol. Res. 107:614-616.

Pumplin, N., and Harrison, M. G. 2009. Live-cell imaging reveals periarbuscular membrane domains and organelle location in Medicago truncatula roots during arbuscular mycorrhizal symbiosis. Plant Physiol. 151:809-819.

Redecker, D., Kodner, R., and Graham, L. E. 2000. Glomalean fungi from the Ordivician. Science 289:1920-1921.

Rosenberger, C. M., Brumell, J. H., and Finlay. B. B. 2000. Microbial pathogenesis: Lipid rafts as pathogen portals. Curr. Biol. 10:R823R825.

Sagan, M., Morandi, D., Tarenghi, E., and Duc, G. 1995. Selection of nodulation and mycorrhizal mutants in the model plant Medicago truncatula (Gaertn) after gamma-ray mutagenesis. Plant Sci. 111:63-71.

Salaün, C., James, D. J., and Chamberlain, L. H. 2004. Lipid rafts and the regulation of exocytosis. Traffic 5:255-264.

Schnabel, E., Journet, E. P., Carvalho-Niebel, F., Duc, G., and Frugoli, J. 2005. The Medicago truncatula SUNN gene encodes a CLV1-like leucine-rich repeat receptor kinase that regulates nodule number and root length. Plant Mol. Biol. 58:809-822.

Schuessler, A., Schwarzott, D., and Walker, C. 2001. A new fungal phylum, the Glomeromycota: Phylogeny and evolution. Mycol. Res. 105:1413-1421

Simons, K., and Ikonen, E. 1997. Functional rafts in cell membranes. Nature 387:569-572.

Simons, K., and Toomre, D. 2000. Lipid rafts and signal transduction. Nat. Rev. Mol. Cell Biol. 1:31-39.

Smith, S. E., and Read, D. J. 2008. Mycorrhizal Symbiosis, Third Edition. Academic Press, London.

Trouvelot, A., Kough, J. L., and Gianinazzi-Pearson, V. 1986. Mesure du taux de mycorhization VA d'un système radiculaire. Recherche de méthodes d'estimation ayant une signification fonctionnelle. Pages 217 221 in: Physiological and Genetical Aspects of Mycorrhizae. V. Gianinazzi-Pearson and S Gianinazzi, eds. INRA Press, Paris.

Valot, B., Negroni, L., Zivy, M., Gianinazzi, S., and Dumas-Gaudot, E. 2006. A mass spectrometric approach to identify arbuscular mycorrhiza-related proteins in root plasma membrane fractions. Proteomics 6:S145-S155

Vierheilig, H., Coughlan, A. P., Wyss, U., and Piché, Y. 1998. Ink and vinegar, a simple staining technique for arbuscular-mycorrhizal fungi. Appl. Environ. Microbiol. 64:5004-5007.

Wulf, A., Manthey, K., Doll, J., Perlick, A. M., Linke, B., Bekel, T., Meyer, F., Franken, P., Küster, H., and Krajinski, F. 2003. Transcriptional changes in response to arbuscular mycorrhiza development in the model plant Medicago truncatula. Mol. Plant-Microbe Interact. 16:306314.

\section{AUTHOR-RECOMMENDED INTERNET RESOURCES}

Medicago EST Navigation System website: medicago.toulouse.inra.fr/Mt/EST

The Mycocalc program:

www2.dijon.inra.fr/mychintec/Mycocalc-prg/download.html

Pôle Bioinformatique Lyonnais Njplot software: biom3.univ-lyon1.fr 